\title{
Stylistic Characteristic of English for Business Contract
}

\author{
Lv Yingli, Liu Yichu \\ Beijing City University, Beijing, 100083
}

Keywords: Contract English; Stylistic Characteristics; Lexical Features; Syntactic Features.

\begin{abstract}
This paper analyzes the stylistic characteristics of contract English from lexical and syntactic features. The lexical feature of contract English are discussed from the aspects of the using of archaism and professional terms, based on the analysis of a large number of typical examples. This paper expounds the following characteristics of syntactic and grammatical features of contract English: long compound sentences which commonly used, nominalization and conditional clauses.

Business contract is a legal document which signed by different legal persons in business activities in order to achieve certain economic benefits. How can we explain business contract English? That is based on the common language of English, which formed and used in business actives. It also can be interpreted as the language with the characteristics of business and legal English. It grows into a linguistic functional variety in a legal and business context with certain special uses and its own laws. Business Contract English is frozen style or formal style, which is the most formal in all kinds of English. At the following article, we will discuss the stylistic features of business contract English from two aspects: vocabulary and syntax.
\end{abstract}

\section{Lexical Features}

One of the main characteristics of English language in business contracts is the frequent use of archaism. Though modern English is inherited and evolved on the basis of archaic and other borrowed words, the use of them are still rare in other languages. The archaism used in contract English is always used as a compound adverb. The composition method of complex adverbs is here, there, and where separately combined with by, after, upon, under, with, to, of and at. For example:

(1) The Buyer hereby orders from the Seller the following goods subject to the following conditions.

(2) Neither party hereto may assign this contract.

This kind of archaism are frequently used in contracts, which is commonly used in contract are: herein=in this, hereunder=under this , thereafter=afterwards, whereas=considering that; but, whereby=by what/which, whereof=of what; of which, etc. The frequent of archaism increase the seriousness and formality of business contracts.

A large number of technical terms can be found when we research business contract English. Technical Terms are internationally universal with the characteristic of accurate and unambiguous. In order to accurately describe and express various documents, terms, links and rights, and obligations of both parties in business activities, Technical Terms has frequent used in it.

(3) Within the validity period of contract, licensee shall not disclose know-how to any third party without prior written consent of licensor.

The meaning of know-how in the example mentioned above is precise, which specifically referring to the production, use and sale of licensed products. That includes all the technical information, design, technical specifications, production procedures, drawings and other information, which are not belong to the scope of patent. The combination of synonyms and nearsynonym is connect with by or and, which make the content more comprehensive and elastic. For example:

(4) Each party to this agreement shall fulfill or perform any of the obligations under this agreement. 
(5)There is in fact a presumption in law that the proposer is applying for a policy in accordance with the insurer's usual terms and conditions.

(6)The Seller will indemnify the Buyer for any losses or damages arising as a result of the Seller's failure to perform any of its obligations arising out of the sale of the goods to the Buyer.

Thus, it can be seen that the juxtaposition of synonyms and near- synonyms in business contract English can fully show the purist of exact and literal meaning of the business contract. The use of juxtaposition also avoiding the loss of semantic differences, and the complexity and conservatism of business contract English are formed.

The word shall not only refers to the "future time", but also represents the legal "responsibilities and obligations to bear" in the business contract. We can know that shall has a strong command and compulsion. This word appears in all contract. For example:

(7)The property in the goods shall pass on delivery.

(8)The Seller guarantees that the goods shall be in accordance with the Seller's specifications.

It can be seen that shall is often used for the names of single and plural, which means the responsibilities and obligations enforced by law. The use of Shall fully embodies the legal effect of the contract.

\section{Syntax Features}

The coherence, length and the use of clause in a business contract are more complicated in compared with common English. The use of a complete long sentence in a business contract can define the rights and obligations to the parties of contract, which excludes the possibility of misinterpretation, misunderstanding and ambiguity. There are many additional components in adverbial and attributive clauses, and it often locates in an obvious position to explain, define or modify the meaning of the main clause.

(1) In case that one or both parties are impossible to perform the duties provided herein on account of force majeure, the party (or parties) in contingency shall inform the other party (or each other) of the case immediately and may, provided the case is duly verified by the competent authorities, delay in performance of or not perform the relevant duties hereunder and may be partially or entirely exempted from the liability for breach of this agreement.

The example mentioned above has 76 words. Firstly, it uses the adverbial clause to guide the sentence by the in case that. The predicate of the main clause is juxtaposed into three parts as following: shall inform... and may...delay...or not perform...and may be...exempted from...The words of provided herein is used as a postposition attribution to modify the duties in adverbial clauses, which plays a precise role in defining the connotation and extension of nouns or concepts. Besides there are prepositional phrases on account of force majeure as adverbial of cause. In addition, the second predicate parts of the main clause also have a conditional adverbial clause guided by provided. All these indicate that they are strict in expression and dignified in sentence.

According to the different uses of sentences, English sentences can be divided into four categories: declarative, interrogative, imperative and exclamatory. Declarative sentences are used to explain, stipulate, and judge that all languages must be objective, plain and generally without expressing personal feelings, and no need to render the atmosphere. Business English contracts should be accurately and objectively commented on the rights and obligations related to the parties involved in the contract. Therefore, the frequency of the declarative sentences in the business contract is quite high. For example:

(2) Part A shall pay the interest on its long-term letter of credit and pay the interest on the loans due to be rendered by party $\mathrm{B}$ in advance. The annual interest rate agreed up on at3\%.

(3) In all classes of insurance, proposer must disclose previous loss experience and all the facts which he could be reasonably expected to know.

Therefore, business contract English has an obvious emphasis on the type of sentence. In order to assure that contract shows accurate and objective statement of facts, the use of exclamatory sentences, imperative sentences and interrogative sentences is seldom used.

Nouns are always used to instead of verbs, adjectives, and long sentences in business English 
contracts, which is called nominalization structure. The noun structure mainly refers to an abstract noun expressing action or state or a non-predicate verb. The structure of nominalization can be seen everywhere in the contract English. For example:

(4) One of the most important factors is that proceeds are transmitted from the buyer to the seller in transactions smoothly.

One of the most important factors is the smooth transmission of proceeds from the buyer to the seller in transactions.

The use of nominalization is to show the logicality and conceptualization of abstract thinking, which can make the style more formal and written. In order to facilitate concise, precise, objective and objective expression of complex concepts, the way of nominalization is different. High nominalization is a prominent feature of contract English, and long and complex nominalization structures are everywhere.

The contract is careful and logical in English language in order to meet the require of regulation of the rights, obligations and responsibilities of the parties with accurate and strict. And under these circumstances, the contract should take into account the various circumstances and to exclude the various exceptions. Besides the obligation both parties should carry out, the contract should consider various situations and solutions. So, there are many conditional clauses in contract terms, especially in payment, liability for breach of contract, force majeure, property disposal and arbitration. The most common expressions in English are the following:

(5) The use of in case (of), for example:

In case the sellers fail to make delivery according to the final delivery schedules, the sellers shall pay the buyers a penalty.

(6) The use of phrase- in the event of or in the event that, for example:

In the event of Party A shall have amended, in-creased or decreased its project of construction work...

There are many conditional clauses in contract English with diversified forms. Sometimes, there are many conditional clauses in a sentence, which are rare in common style.The use of conditionals makes the contents of contract terms more complete and precise, and does not cause any party's economic loss due to improper pragmatics.

\section{Conclusion}

This paper analyzes the stylistic characteristic of business contract English from the aspects of vocabulary and syntax. On the one hand, contract English is concise, precise and precise from the perspective of lexical features. On the other hand, it is characterized by rigorous structure, profound meaning, careful thinking and strong logicality in terms of syntactic characteristic. It emphasis the rigorous, accurate, qualitative and quantitative criteria of the language than follows the general pragmatic principles in business contract English. Thus, avoid disputes and help the parties to maintain the legitimate rights and interests. The understanding and analysis of language characteristics of business contracts can help us to understand the language phenomenon correctly, and improve the effectiveness, appropriateness and communicative competence of language use.

\section{References}

[1] Joos, Martin. The Five Clocks [M]. New York and London: Harcourt Brace Jovanovich, 1961.

[2] Xinghua Huo, Hongyu Qu, Shufen Jiang. The Translation Characteristics of Economic and Trade English [J]. The Journal of Laiyang Agricultural College, 2002, 14(4) 89-91.

[3] Jian Yang. Language Characteristics of Economy and Trade Contract [J]. The Journal of Guangzhou Institute of Financial and Commercial Management, 2001, 13(3): 46-49.

[4] Jida Huang. On the Language Characteristics of English Economic Contract [J]. Journal of Guangxi University Wuzhou Branch, 1999, 9(1): 10-14. 
[5] Ying Liao, Zaishu Mo. Research on International Business English language and Translation [M]. Beijing, Machinery Industry Press, 2004; 129-151. 